\title{
Enhanced production of unstable polymorph by antisolvent crystallization supplying minute-bubbles
}

\author{
M. Matsumoto ${ }^{1}$, Y. Wada ${ }^{2}$, and K. Onoe ${ }^{2}$ \\ ${ }^{1}$ Department of Basic Science, College of Industrial Technology, Nihon University, 2-11-1 Shinei, Narashino, Chiba \\ 275-8576 Japan \\ ${ }^{2}$ Department of Life and Environmental Sciences, Faculty of Engineering, Chiba Institute of Technology, 2-17-1 \\ Tsudanuma, Narashino, Chiba 275-0016 Japan
}

\section{Introduction}

Differences in physical and chemical properties between polymorphic compounds (e.g. solubility, dissolution rate, chemical reactivity, resistance to degradation, bioavailability) are highly significant for the pharmaceutical industry, which requires effective methods to control polymorphism of organic crystals [1, 2]. In particular, to improve the functionality such as solubility or bioavailability for better utilization of organic crystals, the destabilization of crystal structure is indispensable in the crystallization process. One common type of batch-crystallization operation that is widely used in the pharmaceutical, food, and chemical industries is antisolvent crystallization. In this technique, a solute is crystallized from solution by the addition of an antisolvent that effectively reduces the original solubility of the solute and thus increases the supersaturation in the bulk solution $[3,4]$. However, the considerable amount of antisolvent is necessary for the selective crystallization of unstable polymorph, because the generated polymorph changes in order of stable form, metastable form, and unstable form with an increase in supersaturation of the bulk solution [5].

In this study, the micron-scale bubble technique that enables the generation of local supersaturation in the regions around the gas-liquid interfaces was applied to antisolvent crystallization. Minimizing bubble diameter in gas-liquid systems helps achieve the following: i) acceleration of mass transfer and reactive absorption with an increase in the gas-liquid interfacial area, ii) increase in the average residence time of the bubbles with a decrease in buoyancy, and iii) occurrence of interactions at the gas-liquid interface caused by electrification of minute-bubbles [6,7]. Because solute and antisolvent are accumulated near the gas-liquid interfaces by the residence of minute-bubbles with surface potential in the liquid phase for a long period of time, the production of a less stable polymorph and the shift in the overall solid-liquid equilibrium can be expected to occur.
In this paper, we report the combined effects of nitrogen $\left(\mathrm{N}_{2}\right)$ minute-bubbles and methanol as an antisolvent on polymorphism in cases where glycine with three polymorphs of stable $\gamma$-form, metastable $\alpha$ form, and unstable $\beta$-form was selected as an object of crystallization.

\section{Experimental}

\subsection{Measurement of solubility and determination of supersaturation ratio of glycine polymorphs in bulk solution}

Measurement of glycine solubility is essential to understand supersaturation in the bulk solution and to surmise the generation of local supersaturation in the regions around the minute gas-liquid interfaces during antisolvent crystallization. Therefore, the time change in the concentration of dissolved glycine $\left(C_{\mathrm{d}}\right)$ was measured by using a high-performance liquid chromatography system (HPLC, LaChrom Elite, HITACHI Co.) equipped with a refractive index detector and an RSpak DE-413 column (Showa Denko K.K.), when $\gamma$-form, $\alpha$-form, or $\beta$-form glycine was added in excess to methanol-water solution at various values of the mixture ratio of methanol $\left(V_{\mathrm{MeOH}}\right)$, with the solution temperature $\left(T_{\mathrm{s}}\right)$ maintained at $303 \mathrm{~K}$. The commercialgrade glycine (99 vol\% purity, Wako Pure Chemical Industries, Ltd.) was used as most stable $\gamma$-form. The metastable $\alpha$-form and unstable $\beta$-form were prepared using antisolvent precipitation, as suggested by Bouchard et al. [8]. The stationary value of the dissolved glycine concentration was defined as the solubility of each polymorph $\left(C \mathrm{~s}_{\mathrm{i}}, \mathrm{i}=\alpha, \beta, \gamma\right)$ at a specified $V_{\mathrm{MeOH}}$, and supersaturation ratio of glycine polymorphs in the bulk solution $\left(C_{0} / C \mathrm{~s}_{\mathrm{i}}, \mathrm{i}=\alpha, \beta, \gamma\right)$ was calculated from $C \mathrm{~s}_{\mathrm{i}}$ and the initial concentration of glycine $\left(C_{0}\right)$ in the crystallization operation mentioned below, as an index for estimating local supersaturation in the vicinity area of the gas-liquid interfaces. 


\subsection{Production of glycine polymorphs by antisolvent crystallization supplying N2 minute- bubbles}

The schematic of the semi-batch crystallization apparatus is shown in Fig. 1. In a crystallization vessel, methanol as an antisolvent was mixed into the saturated glycine solution at $T_{\mathrm{s}}$ of $303 \mathrm{~K}$. $V_{\mathrm{MeOH}}$ was varied in the range of $20-60$ vol\% with methanol volume of $60-180$ $\mathrm{m} l$ to control supersaturation ratio of glycine in the bulk solution. $C_{0}$ was in the range of 1.44 to $2.88 \mathrm{~mol} / l$ due to the change in the mixture volume of the saturated glycine solution to $120-240 \mathrm{ml}$ under constant total volume of $300 \mathrm{ml}$. While mixing methanol with the saturated glycine solution, $\mathrm{N}_{2}$ bubbles with different values of the average bubble diameter $\left(d_{\mathrm{bbl}}\right)$ were continuously supplied to $300 \mathrm{~m} l$ of the mixed solution and glycine was crystallized. Minute-bubbles with a $d_{\mathrm{bbl}}$ of $10 \mu \mathrm{m}$ were generated using a self-supporting bubble generator by increasing the impeller shear rate under reduced pressure [7,9], with the rotation rate maintained at $1500 \mathrm{~min}^{-1}$ and the $\mathrm{N}_{2}$ flow rate $\left(F_{\mathrm{N} 2}\right)$ controlled at $7.35 \mathrm{mmol} /(l \cdot \mathrm{min})$. Bubbles with a $d_{\mathrm{bbl}}$ of 600,900 , or $2000 \mu \mathrm{m}$ were obtained using a dispersing-type generator, and $d_{\mathrm{bbl}}$ was varied by changing the hole size $(65-300 \mu \mathrm{m})$ on the dispersing plate at the same $F_{\mathrm{N} 2}$ mentioned above. Antisolvent crystallization free of $\mathrm{N}_{2}$ bubbles was carried out for comparison using a propeller type mixer with four blades. $T_{\mathrm{s}}$ during crystallization was maintained constant at $303 \mathrm{~K}$ using a thermostat bath, and the crystallization time $\left(t_{\mathrm{c}}\right)$ was controlled within 5 $\min$.

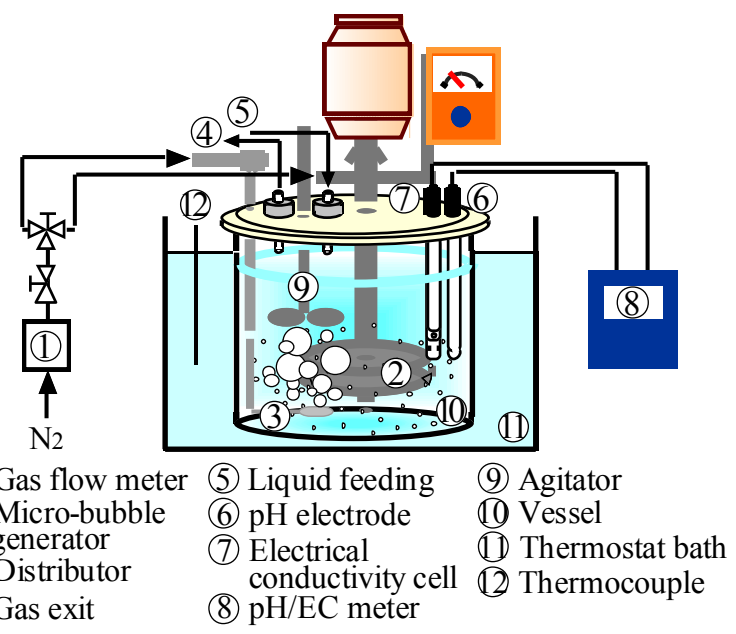

Figure 1. Semi-batch crystallization apparatus.

After the crystallization progressed for a specified length of time, the suspension was filtered and dried at $343 \mathrm{~K}$ for $60 \mathrm{~min}$ under reduced pressure. Glycine polymorphs were identified by X-ray diffraction (XRD, RINT2100, Rigaku Co.), and the selectivity of polymorphs $\left(S_{\mathrm{i}}, \mathrm{i}=\alpha\right.$, $\beta, \gamma)$ in a product mixture was determined from the peak area ratio of XRD.

\section{Results and discussion}

\subsection{Relationship between mixture ratio of methanol and solubility or supersaturation ratio of glycine polymorphs in bulk solution}

$C_{0} / C \mathrm{~s}_{\mathrm{i}}$ was determined by $C_{0}$ in the crystallization operation and $C \mathrm{~s}_{\mathrm{i}}$ measured at various $V_{\mathrm{MeOH}}$ values in order to speculate the degree of local supersaturation at the minute gas-liquid interfaces. Fig. 2 shows the time changes in $C_{\mathrm{d}}$ and $S_{\mathrm{i}}$ of solid glycine when $\beta$-form glycine was added in excess to methanol-water solution at a $V_{\mathrm{MeOH}}$ of $40 \mathrm{vol} \%$.

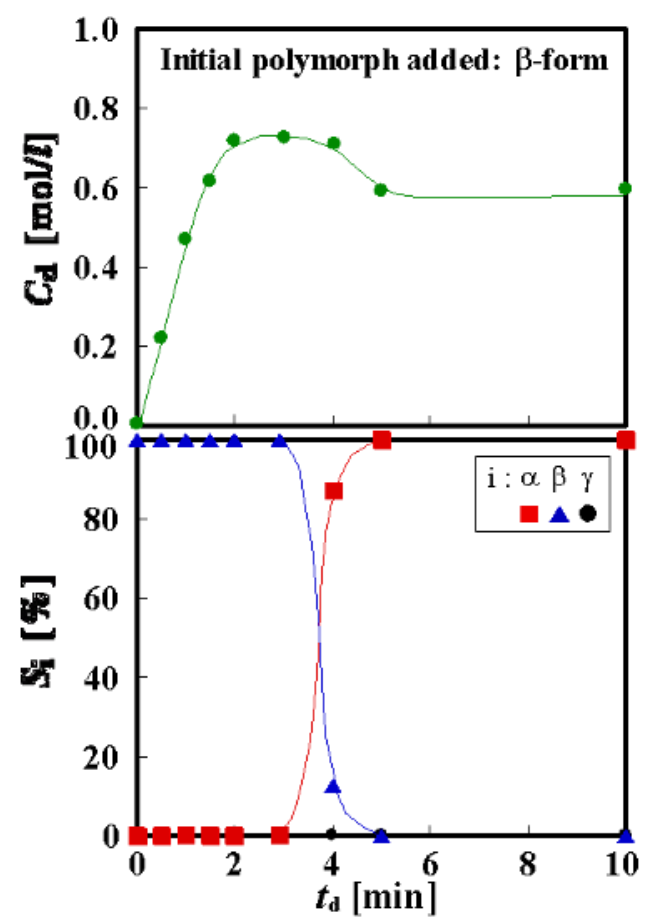

Figure 2. Time changes in $C_{\mathrm{d}}$ and $S_{\mathrm{i}}$ of solid glycine.

$C_{\mathrm{d}}$ using $\beta$-form had two stationary values at 0.75 and $0.60 \mathrm{~mol} / l$ because unstable $\beta$-form transformed completely to metastable $\alpha$-form at the dissolution time $\left(t_{\mathrm{d}}\right)$ of $5 \mathrm{~min}$. Meanwhile, $C_{\mathrm{d}}$ of $\alpha$-form and $\gamma$-form increased gradually with an increase in $t_{\mathrm{d}}$, and achieved the stationary-state level at 0.60 and $0.55 \mathrm{~mol} / \mathrm{l}$, respectively, and the polymorphic transformation from metastable $\alpha$-form to stable $\gamma$-form was not observed within $10 \mathrm{~min}$ dissolution. Therefore, the stationary-state level of dissolved $\beta$-form concentration was determined at $0.75 \mathrm{~mol} / l$. The stationary values of $C_{\mathrm{d}}$ using $\beta$-form, $\alpha$-form, and $\gamma$-form were measured by varying $V_{\mathrm{MeOH}}$, and were defined as $C \mathrm{~s}_{\beta}, C \mathrm{~s}_{\alpha}$, and $C \mathrm{~s}_{\gamma}$. The obtained values of $C \mathrm{~s}_{\mathrm{i}}$ and $C_{0} / C \mathrm{~s}_{\mathrm{i}}$, and $C_{0}$ were plotted against $V_{\mathrm{MeOH}}$ as shown in Fig. 3. 


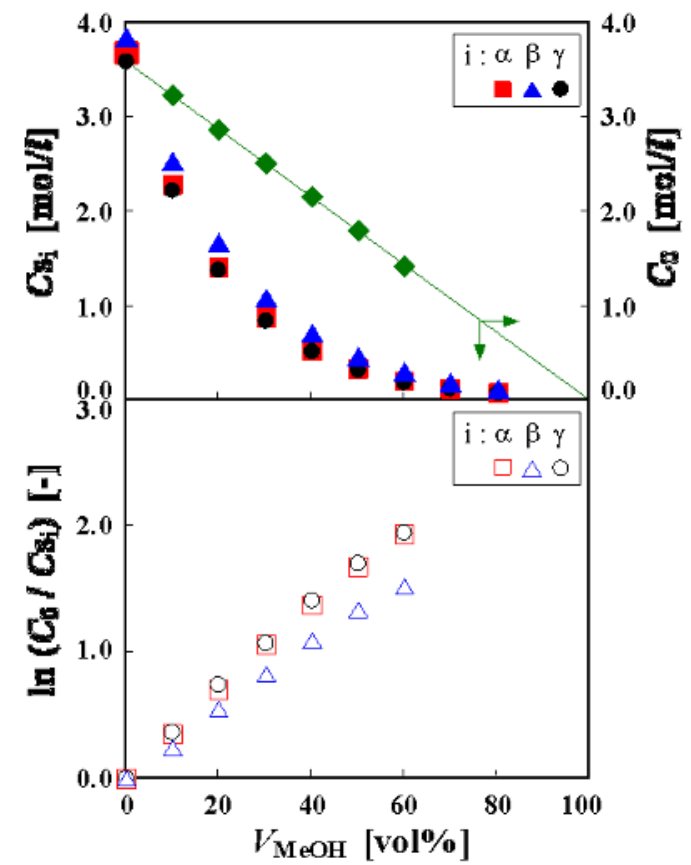

Figure 3. Relation between $V_{\mathrm{MeOH}}$ and $C_{0}, C \mathrm{~s}_{\mathrm{i}}, C_{0} / C \mathrm{~s}_{\mathrm{i}}$.

The tendencies of $C \mathrm{~s}_{\alpha}$ and $C \mathrm{~s}_{\beta}$ to decrease with an increase in $V_{\mathrm{MeOH}}$ had similarity to that observed in $\gamma$ form, and the solubility was in the order of $\beta$-form $>\alpha$ form $>\gamma$-form at all values of $V_{\mathrm{MeOH}}$. Accordingly, $C_{0} / C \mathrm{~s}_{\beta}, C_{0} / C \mathrm{~s}_{\alpha}$, and $C_{0} / C \mathrm{~s}_{\gamma}$ increased with an increase in $V_{\mathrm{MeOH}}$, and higher supersaturation is necessary to crystallize $\beta$-form glycine.

\subsection{Comparison of antisolvent crystallization of glycine polymorphs}

So as to clarify the effects of local supersaturation at the minute gas-liquid interfaces on glycine polymorphism, antisolvent crystallization with $\mathrm{N}_{2}$ bubbles at various $d_{\mathrm{bbl}}$ values or without bubbles was performed. Under all the experimental conditions investigated in this work, the solution $\mathrm{pH}$ during antisolvent crystallization remained almost constant at 6.2 independent of $t_{\mathrm{c}}, V_{\mathrm{MeOH}}$, and $d_{\mathrm{bbl}}$. This is because of the $\mathrm{pH}$ buffering effects of glycine induced by the amino group and carboxylic group of glycine chemical structure. Fig. 4 shows the comparison of the relationship between $V_{\mathrm{MeOH}}$ and the concentration of polymorph produced $\left(G_{\mathrm{i}}, \mathrm{i}=\alpha, \beta, \gamma\right)$ at a $t_{\mathrm{c}}$ of $0.5 \mathrm{~min}$.

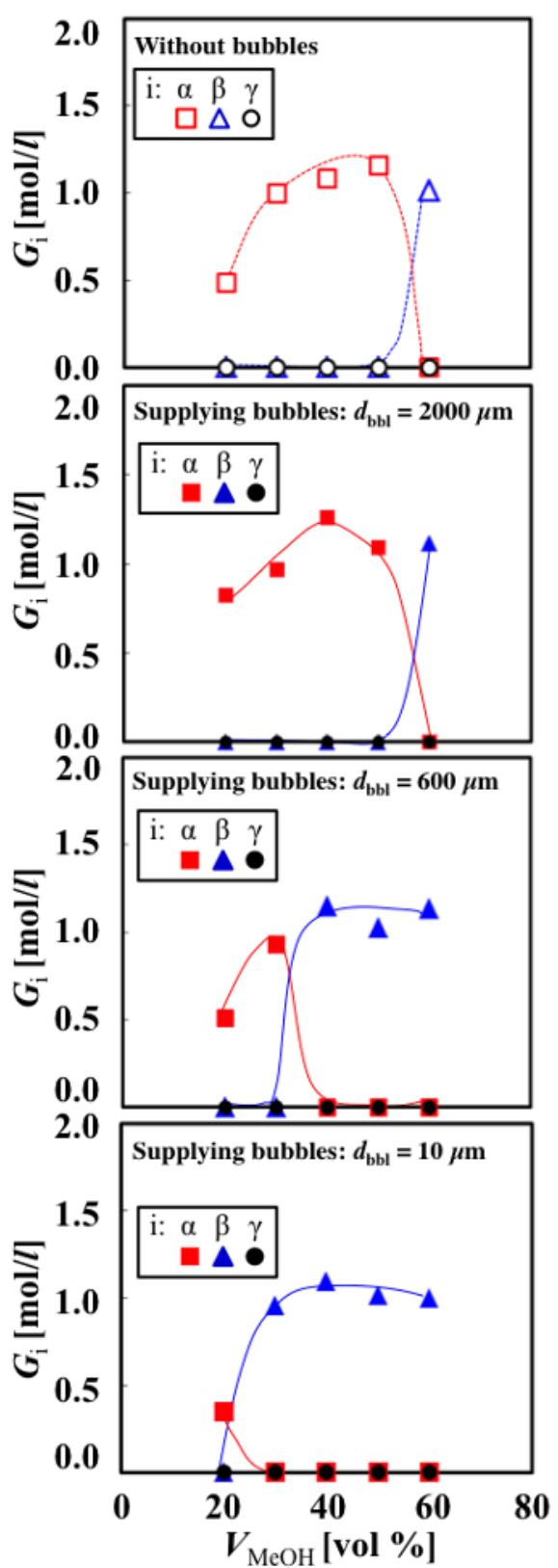

Figure 4. Effects of $V_{\mathrm{MeOH}}$ on $G_{\mathrm{i}}\left(t_{\mathrm{c}}: 0.5 \mathrm{~min}\right)$.

$G_{\alpha}$ and $G_{\beta}$ were determined from the total weight of the produced glycine and $S_{\mathrm{i}}$. The most stable $\gamma$-form was not obtained under all the experimental conditions employed. When $\mathrm{N}_{2}$ bubbles were not supplied, metastable $\alpha$-form was dominant product at $V_{\mathrm{MeOH}}$ lower than $50 \mathrm{vol} \%$, and the production of unstable B-form proceeded mainly at a $V_{\mathrm{MeOH}}$ of $60 \mathrm{vol} \%$. Besides, the dependence of $G_{\beta}$ on $V_{\mathrm{MeOH}}$ observed supplying minutebubbles at a $d_{\mathrm{bbl}}$ of $2000 \mu \mathrm{m}$ was approximately similar to those obtained without supplying bubbles. When $\mathrm{N}_{2}$ minute-bubbles with a $d_{\mathrm{bbl}}$ of $10 \mu \mathrm{m}$ were supplied, at $V_{\mathrm{MeOH}}$ greater than $30 \mathrm{vol} \%$ B-form with high-selectivity was crystallized. At a $d_{\mathrm{bbl}}$ of $600 \mu \mathrm{m}, \beta$-form production was predominantly in the $V_{\mathrm{MeOH}}$ range over $40 \mathrm{vol} \%$. Generally, the addition ratio of antisolvent at a range over about $50 \mathrm{vol} \%$ has a tendency to generate unstable $\beta$-form [8, 10-11]. Bouchard et al. reported that the use of methanol as an antisolvent was more appropriate for $\beta$-form production, because the transformation rate from 
unstable $\beta$-form to matastable $\alpha$-form decreased with an increase in the addition ratio and with a decrease in carbon number of antisolvent [8]. Compared to the previous studies, our experimental results indicated that not only increasing $V_{\mathrm{MeOH}}$ but also bubble injection and minimizing bubble size led to the enhanced production of unstable $\beta$-form caused by the inhibition of polymorphic transformation from $\beta$-form to $\alpha$-form.

\subsection{Effects of supersaturation ratio in bulk solution on production rate of unstable B-form}

From the results obtained at various $d_{\mathrm{bbl}}$ and $V_{\mathrm{MeOH}}$ values, the production rate of $\beta$-form $\left(r_{\beta}\right)$ were calculated from the gradient of the time change in concentration of $\beta$-form glycine produced at a $t_{\mathrm{c}}$ of $0.5 \mathrm{~min}$. The correlation between $\ln \left(C_{0} / C \mathrm{~s}_{\beta}\right)$ and $r_{\beta}$ as a function of $d_{\mathrm{bbl}}$ is shown in Fig. 5. During antisolvent crystallization without the bubble supply $\beta$-form was crystallized mainly at a $\ln \left(C_{0} / C \mathrm{~s}_{\beta}\right)$ of 1.5 . The crystallization region of $\beta$-form was expanded because of minimizing bubble diameter, and $\ln \left(C_{0} / C \mathrm{~s}_{\beta}\right)$ reached to 0.8 with a decrease in $d_{\text {bbl }}$ up to $10 \mu \mathrm{m}$. It was suggested that local supersaturation in the regions around the minute gasliquid interfaces increased about twice compared with the surrounding bulk solution, and the generation of numerous local supersaturation regions near the gasliquid interfaces decreased $C_{0} / C \mathrm{~s}_{\beta}$ necessary for the selective crystallization of unstable $\beta$-form.

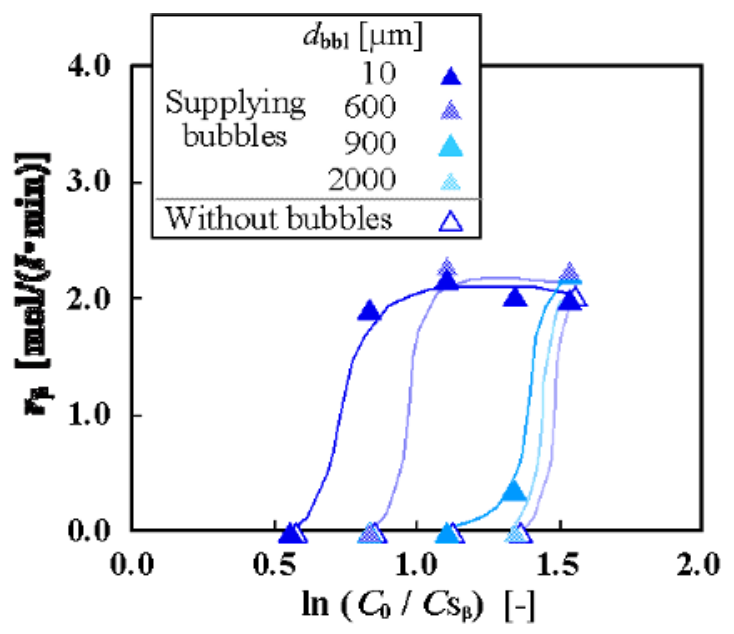

Figure 5. Effects of $C_{0} / C \mathrm{~s}_{\beta}$ on $r_{\beta}\left(t_{\mathrm{c}}: 0.5 \mathrm{~min}\right)$.

Investigation about the electric charge on the minutebubble surface to clarify the occurrence of interactions at the gas-liquid interfaces revealed that the zeta potential of minute-bubbles with $d_{\mathrm{bbl}}$ of $10-30 \mu \mathrm{m}$ was negative value between -50 and $-100 \mathrm{mV}[6,7,9]$, and the presence of glycine and methanol led to the zeta potential approach to $0 \mathrm{mV}$ [12]. These findings indicated that glycine and methanol concentrations increased locally in the vicinity area of minute gas-liquid interfaces. Thus, it can be stated that minute-bubble injection changes locally the relationship between $V_{\mathrm{MeOH}}$ and $C_{0} / C \mathrm{~s}_{\beta}$ in the surrounding area of minute gas-liquid interfaces.

\section{Conclusion}

The production of glycine with three polymorphs was carried out using antisolvent crystallization with/without minute-bubble formation. Supersaturation ratio in the bulk solution was determined from initial concentration of glycine in the crystallization operation and the solubility of each polymorph measured at various values of mixture ratio of methanol. The following results were obtained: (1) bubble injection and minimizing bubble diameter decreased supersaturation ratio in the bulk solution necessary for the selective crystallization of unstable $\beta$-form; (2) minute-bubble injection changed locally the relationship between the mixture ratio of methanol and supersaturation ratio at the minute gasliquid interfaces.

\section{References}

1. M. Blanco, J. Coello, H. Iturriaga, S. Maspoch, C. Pérez-Maseda, Anal. Chim. Acta 407247 (2000)

2. M. Rabesiaka, M. Sghaier, B. Fraisse, C. Porte, J.L. Havet, E. Dichi, J. Cryst. Growth 3121860 (2010)

3. J.W. Mullin, Crystallization, $3^{\text {rd }}$ ed., ButterworthHeinemann, London, 1993

4. M. Uusi-Penttilä, K.A. Berglund, J. Cryst. Growth 166967 (1996)

5. H. Takiyama, Adv. Powder Technol. 23273 (2012)

6. M. Matsumoto, Y. Morita, M. Yoshinaga, S. Hirose, K. Onoe, J. Chem. Eng. Jpn. 42 s242 (2009)

7. M. Matsumoto, T. Fukunaga, K. Onoe, Chem. Eng. Res. Des. 881624 (2010)

8. A. Bouchard, G.W. Hofland, G.J. Witkamp, J. Chem. Eng. Data 521626 (2007)

9. M. Matsumoto, M. Isago, K. Onoe, Bull. Soc. Sea Water Sci. Jpn. 58475 (2004)

10. E. Fischer, Ber. Deut. Chem. Ges. 382914 (1905)

11. E.S. Ferrari, R.J. Davey, W.I. Cross, A.L. Gillon, C.S. Towler, Cryst. Growth Des. 353 (2003)

12. M. Matsumoto, Y. Wada, M. Suzuki, M. Yoahida, K. Onoe, Bull. Soc. Sea Water Sci. Jpn. 65301 (2011) 